\title{
Aspergillus flavus and Aflatoxin Contamination of Leguminous Trees of the Sonoran Desert in Arizona
}

\author{
María L. Boyd and Peter J. Cotty
}

Southern Regional Research Center, USDA-ARS, 1100 Robert E. Lee Blvd., New Orleans, LA 70124.

Accepted for publication 31 May 2001.

\section{ABSTRACT}

Boyd, M. L., and Cotty, P. J. 2001. Aspergillus flavus and aflatoxin contamination of leguminous trees of the Sonoran Desert in Arizona. Phytopathology 91:913-919.

Aspergillus spp. in section Flavi were frequently associated with desert tree legumes in uncultivated areas of the Sonoran Desert. Of 270 samples of debris and fruits of mesquite (Prosopis spp.), ironwood (Olneya tesota), acacia (Acacia spp.), and palo verde (Cercidium and Parkinsonia spp.), $87 \%$ were positive for $A$. flavus (S and $\mathrm{L}$ strains) and A. tamarii. A. flavus was the most common species (87\%) among the 3,763 isolates examined. Mesquite pods were both the substrate from which A. flavus was recovered most frequently and the substrate from native habitats with the greatest aflatoxin content. In vitro, most desert legumes supported significant growth, reproduction, and aflatoxin production by A. flavus, with mesquite pods yielding $1 \times 10^{10}$ propagules $/ \mathrm{g}$ and $5,000 \mu \mathrm{g} / \mathrm{kg}$ of aflatoxin $\mathrm{B}_{1}$. Twenty percent of legume pods collected in the desert contained measurable quantities of aflatoxin, ranging from 1 to $>2,500 \mu \mathrm{g} / \mathrm{kg}$. Insect-damaged mesquite pods had significantly higher aflatoxin than intact pods. Legumes are apparently important reservoirs of aflatoxinproducing fungi and significant sources of aflatoxin contamination in the native Sonoran Desert habitats of Arizona.

Additional keywords: bruchid beetles, cattle feed, Cercidium, Olneya, Parkinsonia, Prosopis.
Fungi in Aspergillus section Flavi are widely distributed and several species in this section produce aflatoxins (14,26,37). Aflatoxins are potent carcinogens and their presence in food is regulated in most countries through legislation (14). In the United States, aflatoxin content of foods may not exceed $20 \mu \mathrm{g} / \mathrm{kg}$ (14). Aspergillus flavus contaminates many crops with aflatoxins, including corn, peanut, cottonseed, and tree nuts. Many studies of aflatoxin-producing fungi and aflatoxin contamination have been conducted in agricultural areas (14). Infection and contamination of plant parts predisposed by stress or insect damage is most common $(7,47,49)$. Aflatoxin production also occurs on soybeans and other leguminous annuals (41-43) and is often considered a postharvest problem. The level of aflatoxin contamination in nonagricultural areas and in uncultivated plants remains largely unexplored. In the Sonoran Desert, A. flavus is common in soil and in plant and animal debris $(8,9)$.

In arid environments, desert legumes are key species that fix nitrogen, deposit organic matter, prevent desertification, act as nursing plants to cacti, and provide vital food and shelter for desert fauna $(3,27)$. Humans exploit desert legumes for wood, cattle feed, and even food. Mesquites (Prosopis spp.) are some of the most abundant trees in the bottomlands (bajadas) and plains of the Sonoran Desert. Unlike other members of Fabaceae, mesquite pods do not dehisce (6). The tough and leathery pods are rich in carbohydrates, which accumulates in the mesocarp. These pods are essential food for desert animals (27). Large mammals frequently consume whole pods and the seed are coprophitically transmitted $(16,30)$. The seeds enclosed in a fibrous and stony endocarp are high in protein (16). The indigenous peoples of the southwest traditionally consumed mesquite pods as a ground meal or flour $(19,23)$. Other common leguminous trees in the Sonoran

Corresponding author: P. J. Cotty; E-mail address: pjcotty@srrc.ars.usda.gov

Publication no. P-2001-0706-01R

This article is in the public domain and not copyrightable. It may be freely reprinted with customary crediting of the source. The American Phytopathological Society, 2001.
Desert include palo verde (Cercidium and Parkinsonia spp.), acacia (Acacia spp.), and ironwood (Olneya tesota). Pods of these trees have also been used as food by indigenous peoples and are important wildlife food sources. It is not unusual to find these common desert leguminous trees near agricultural fields of the Sonoran Desert. A. flavus has been reported on seed and gum exudates of Prosopis spp. $(22,44)$. The objective of the current study was to evaluate the importance of leguminous trees as reservoirs of aflatoxin-producing fungi and as sources of aflatoxin exposure in natural habitats. Laboratory tests were used to evaluate the suitability of leguminous fruits as substrates for production of both A. flavus propagules and aflatoxins. Incidence of A. flavus and closely related fungi in plant debris and pods of common leguminous trees collected in the Sonoran Desert was quantified. Litter and pod collections were tested for aflatoxins to establish the extent to which mesquites in natural habitats and nearby agricultural lands become contaminated.

\section{MATERIALS AND METHODS}

Incidence and density of Aspergillus section Flavi. Plant debris and pods of common leguminous trees and shrubs were collected from several locations in the Sonoran Desert of Arizona (Table 1). Samples were stored in cotton cloth bags, oven dried for $48 \mathrm{~h}$ at $50^{\circ} \mathrm{C}$, and stored until use at room temperature $(23 \pm$ $2{ }^{\circ} \mathrm{C}$ ) in plastic bags to avoid absorption of moisture from the air. Pod samples were ground with a Biohomogenizer (Biospec Products, Bartlesville, OK) for at least 3 min or until a fine homogeneous powder was obtained. Plant debris or ground pod sample $(10 \mathrm{~g})$ was suspended in $50 \mathrm{ml}$ of sterile water and Triton X-100 $(0.001 \%$, vol/vol $)$, in a $100-\mathrm{ml}$ flask, stirred for at least $15 \mathrm{~min}$, serially diluted, and plated on modified Rose Bengal agar media (M-RB, 11). Plates were incubated for 5 to 7 days at $37^{\circ} \mathrm{C}$. CFU (limit of detection $6 \mathrm{CFU} / \mathrm{g}$ ) for members of the Aspergillus section Flavi group were calculated from the appropriate dilution. A maximum of 20 colonies per sample were transferred to 5/2 agar (5\% V8 juice, 2\% agar) and A. flavus-parasiticus agar (AFPA) 
(34), and incubated 5 days at 37 and $31^{\circ} \mathrm{C}$, respectively. The different species and strains of the group were identified from morphological and colony characteristics on both 5/2 agar and AFPA. To assess the presence and composition of the community of Aspergillus section Flavi in samples containing $<6 \mathrm{CFU} / \mathrm{g}$, aliquots $(\approx 0.35 \mathrm{~g})$ were sprinkled on M-RB plates, $200 \mu \mathrm{l}$ of water was added, and the aliquot was spread over the agar surface. Samples were scored as positive or negative for Aspergillus spp. Actual CFU values were not calculated for samples containing $<6$ $\mathrm{CFU} / \mathrm{g}$ because high densities of other fungi made quantification inaccurate. However, colonies were transferred to appropriate media for identification.

In vitro production of propagules and aflatoxins. The potential of pods from mesquite, palo verde, acacia, and ironwood plants as substrates for aflatoxin and propagule production by $A$. flavus was determined in vitro. Mature pods were broken into pieces between 3 and $7 \mathrm{~cm}$ in length. For each of the four legumes, pod pieces from multiple collections were combined. Pod pieces $(\approx 5 \mathrm{~g})$ were arranged around a $50-\mathrm{ml}$ uncapped glass vial positioned in the center-bottom of a 250-ml flask. Humidity within flasks was elevated by adding $20 \mathrm{ml}$ of water to each vial. Flasks were autoclaved and inoculated with $2 \mathrm{ml}$ of an aqueous conidial suspension containing $0.5 \times 10^{6}$ conidia/ml of the highly toxigenic A. flavus L strain isolate AF-13 (10). Sterile deionized water $(2 \mathrm{ml})$ was added to the controls. The flasks were plugged with BugStopper plugs (Whatman, Inc., Clifton, NJ) that allow gas exchange but prevent desiccation, and incubated at $31^{\circ} \mathrm{C}$ for 7 days. After incubation, $50 \mathrm{ml}$ of water with $0.5 \%$ (vol/vol) Tween 80 was added to each flask, which was subsequently shaken with an orbital shaker at $300 \mathrm{rpm}$ for $1 \mathrm{~h}$ to dislodge conidia. The resulting suspension ( $1 \mathrm{ml}$ ) was dilution plated on $\mathrm{M}-\mathrm{RB}$ agar to estimate CFU yield. The remaining pod pieces and suspension were homogenized in a blender (Waring, New Hartford, CT) for $2 \mathrm{~min}$. The homogenate was transferred to a polypropylene jar (Nalgene, Rochester, NY), $50 \mathrm{ml}$ of acetone was added, and the mixture was allowed to settle overnight. The solution was decolorized with a zinc acetate/aluminum chloride solution used for cottonseed aflatoxin analyses (31), and $5 \mathrm{~g}$ of diatomaceous earth was added. After mixing (20 s) and settling (1 h), the solution was passed through a Whatman No. 4 filter paper and the aflatoxins

TABLE 1. Locations, number of sampling sites, and number of samples of legume debris and pods collected in the Sonoran Desert of Arizona, 1998 to 2000

\begin{tabular}{lccc}
\hline & & \multicolumn{2}{c}{ Samples } \\
\cline { 3 - 4 } Location & Sites & Debris & Pods \\
\hline Buckeye & 5 & 0 & 24 \\
Freeman & 16 & 53 & 28 \\
Maricopa & 4 & 0 & 4 \\
OPCNM & 9 & 17 & 6 \\
Painted Rock & 3 & 0 & 6 \\
SNPz & 6 & 22 & 7 \\
Texas Hill & 7 & 34 & 6 \\
Wellton & 13 & 39 & 24 \\
Total & 63 & 165 & 105 \\
\hline
\end{tabular}

y Organ Pipe Cactus National Monument.

z Saguaro National Park. were extracted as described for cottonseed (13). The aflatoxins were separated by thin-layer chromatography and quantified as described below. Using the same procedure in independent tests, production of $A$. flavus propagules and aflatoxins was compared between mature and immature whole mesquite pods; between mature mesquite seed and pericarp pieces; among seedless pods of ironwood, acacia, palo verde, and mesquite; and among mature seeds of corn, cottonseed, mesquite, and palo verde. In each test, treatments were replicated three times with similarly replicated uninoculated controls for each substrate. Each experiment was performed twice.

Aflatoxin-producing potential of $A$. flavus isolates. Fifty isolates of $A$. flavus from mesquite samples were tested for aflatoxin production in vitro. Isolates were grown in $70 \mathrm{ml}$ of Adye and Matales medium (2) with $\mathrm{NH}_{4} \mathrm{SO}_{4}$ at $3 \mathrm{~g} /$ liter as the sole nitrogen source as previously described (13). Erlenmyer flasks $(250 \mathrm{ml})$ were inoculated with approximately $5 \times 10^{3}$ spores per $\mathrm{ml}$ and incubated on a shaker at $150 \mathrm{rpm}, 31^{\circ} \mathrm{C}$, in the dark. Five days after incubation, $70 \mathrm{ml}$ of acetone was added to each flask to lyse the mycelium and extract the aflatoxins. After adding the acetone, flasks settled overnight at room temperature, and the solution was passed through Whatman No. 4 filter paper. The filtrate $(100 \mathrm{ml})$ was extracted following the method of Cotty and Bayman (13). Extracts were either diluted or concentrated to permit accurate densitometry and aflatoxin $\mathrm{B}_{1}$ was quantified on thin-layer chromatography plates by scanning densitometry (35). The mycelium was collected on Whatman No. 4 filter paper, oven dried, and its weight recorded. The limit of detection was $1 \mathrm{ng}$ aflatoxin $\mathrm{B}_{1} / \mathrm{g}$ of mycelium.

Aflatoxins in natural habitats. Samples of both immature and mature pods collected in the Sonoran Desert were ground and assayed for aflatoxin as described above. All samples determined to be positive through thin-layer chromatography were evaluated with AflaTest P-aflatoxin testing system columns (Vicam, Watertown, MA), to confirm the presence of aflatoxin $\mathrm{B}_{1}$. Methylene chloride extracts containing aflatoxins were evaporated to dryness, and dissolved in $1 \mathrm{ml}$ of aqueous methanol (20\%, vol/vol). The entire sample was passed through an AflaTest $\mathrm{P}$ column, the column was washed twice with $5 \mathrm{ml}$ of deionized water, and aflatoxins were eluted with $1 \mathrm{ml}$ of methanol. The eluted methanol fraction was evaporated to dryness, dissolved in methylene chloride, and subjected to thin-layer chromatography and quantitative densitometry as described above. Following confirmation with the AflaTest P columns, four samples were also subjected to the official method of the American Oil Chemists' Society (AOCS, Official Method Aa 9-86), for confirming the presence of aflatoxins with trifluroacetic acid (TFA) (31). The AOAC method relies on conversion of aflatoxin $B_{1}$ to its hemiacetal (aflatoxin $\mathrm{B}_{2 \mathrm{a}}$ ) as proof of identity. The required standards and a $\mathrm{B}_{2 \mathrm{a}}$ standard (Sigma-Aldrich, St. Louis, MO) were used when confirming samples.

Statistical analyses. Statistical analyses were performed using Statistica version 4.5, SAS version 8.0, and Excel version 4.0. All data were tested for normality and, if not normally distributed, data was transformed. Log transformations were used for aflatoxin and $\mathrm{CFU}$ values. Percentages were transformed by the arcsine of the square root as recommended by Sokal and Rolf (46). Student's $t$ tests and analysis of variance (ANOVA) were applied

TABLE 2. Incidence and quantity of Aspergillus tamarii and A. flavus in four common legumes of the Sonoran Desert

\begin{tabular}{|c|c|c|c|c|c|c|}
\hline \multirow[b]{2}{*}{ Samples ${ }^{\mathrm{z}}$} & \multirow[b]{2}{*}{$n$} & \multicolumn{2}{|c|}{ A. tamarii } & \multicolumn{2}{|c|}{ A. flavus } & \multirow[b]{2}{*}{$\mathrm{S}$ strain $(\%)$} \\
\hline & & Incidence $(\%)$ & $\mathrm{CFU} / \mathrm{g}$ & Incidence $(\%)$ & $\mathrm{CFU} / \mathrm{g}$ & \\
\hline Debris & 165 & 75 & $4.0 \times 10^{3}$ & 99 & $6.3 \times 10^{3}$ & 7 \\
\hline Pods & 105 & 16 & $1.2 \times 10^{2}$ & 70 & $1.6 \times 10^{6}$ & 15 \\
\hline Overall & 270 & 52 & $2.9 \times 10^{3}$ & 87 & $5.8 \times 10^{5}$ & 10 \\
\hline
\end{tabular}

$\overline{\mathrm{z}}$ Includes mesquite, ironwood, acacia, and palo verde. 
as appropriate. Results from tests with multiple comparisons were subjected to ANOVA. In tests where significance $(P=0.05)$ was observed, separation of means was performed with Fisher's least significant difference (LSD) test. In vitro tests were performed twice and experiment-treatment interactions assessed with ANOVA. If an experiment-treatment interaction was found, data from both experiments are shown.

\section{RESULTS}

Incidence and density of Aspergillus section Flavi. A total of 270 samples of debris and plant parts from leguminous trees were collected from October 1997 to March 2000 in 16 independent collection trips to 63 sites in eight different areas of the Sonoran Desert of Arizona (Table 1). Both plant debris and pod samples from desert legumes were positive for A. flavus. Of the 270 samples evaluated, $99 \%$ of debris and $70 \%$ of pod samples contained A. flavus. (Table 2). No other aflatoxin-producing species was detected in the samples. The only other species within section Flavi detected was $A$. tamarii, a species that does not produce aflatoxins. A. tamarii was found in $52 \%$ of the samples. A. tamarii had a fourfold lower incidence on pod samples than A. flavus. However, both $A$. flavus and $A$. tamarii were more common on legume debris than on pods. The average density of $A$. tamarii over all samples was 200 times less than the average density of $A$. flavus. Both the $\mathrm{S}$ and $\mathrm{L}$ strains of A. flavus were found in debris and pods from all the surveyed legumes. The $\mathrm{L}$ strain was more prevalent than the $\mathrm{S}$ strain in both debris and pods. Overall, average incidence of the $\mathrm{S}$ strain was slightly higher on pods than on debris. There were variations in the density of A. flavus on material from the different legumes tested (Fig. 1). Mesquite pods had significantly higher densities $(P<0.001$, Student's $t$ test $)$ of A. flavus than mesquite debris. However, the density of A. flavus in debris was significantly higher than on pods for both palo verde and ironwood $(P<0.001$ and $P=0.004$, respectively).

In vitro production of propagules and aflatoxins. Inoculation experiments of corn, cotton, mesquite, and palo verde with a highly toxigenic strain of A. flavus (AF-13) showed the highest production of $A$. flavus propagules on mesquite seed, and the highest aflatoxin $\mathrm{B}_{1}$ production in cottonseed (Table 3). A. flavus

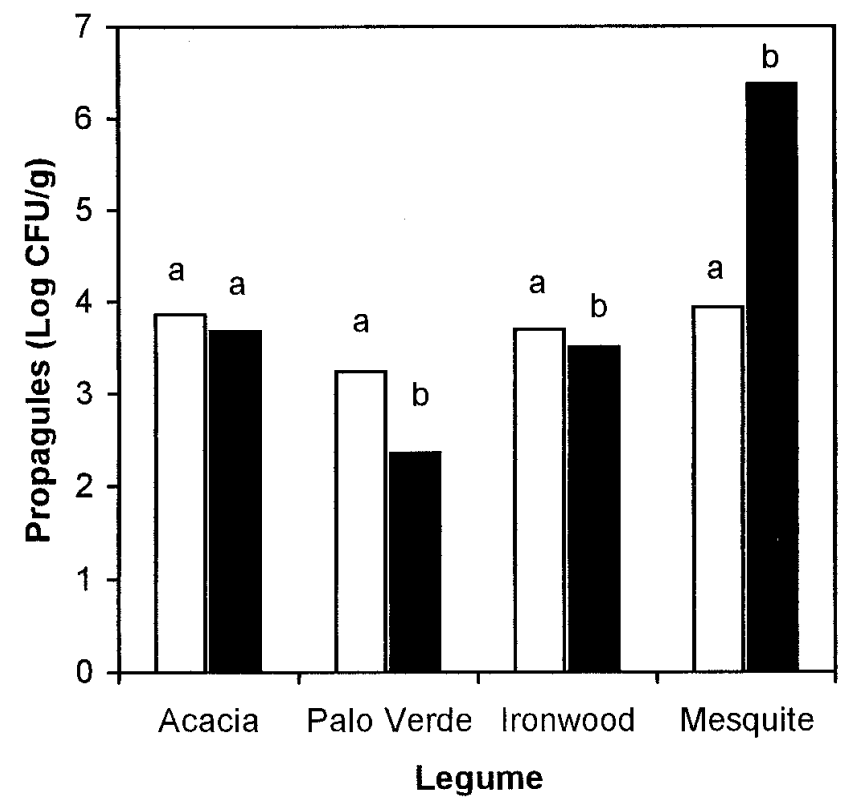

Fig. 1. Density of Aspergillus flavus in pods and debris of four common legumes of the Sonoran Desert, $\square=$ debris, and $\boldsymbol{\square}=$ pods. Bars with the same letter for each legume group do not differ significantly at $P=0.05$ as determined by Student's $t$ test.
(AF-13) produced significantly more propagules per gram of substrate on mesquite seed than on palo verde, corn, or cottonseed. There were no significant differences in CFU per gram of AF-13 among palo verde, corn, or cottonseed. Nevertheless, aflatoxin production was significantly higher in cottonseed than in any other substrate tested (Table 3). Production of aflatoxin $B_{1}$ in cottonseed was 30 times higher than in other substrates. Average aflatoxin $\mathrm{B}_{1}$ production in mesquite was significantly higher than on corn. However, average aflatoxin $\mathrm{B}_{1}$ production for palo verde seed was significantly higher than on corn for only one of the tests performed (Table 3 ). Aflatoxin $\mathrm{B}_{1}$ production was lowest on corn. Seeds of mesquite and palo verde supported similar quantities of aflatoxin $\mathrm{B}_{1}$.

A. flavus grew and produced both propagules and aflatoxins on the pericarp of all the desert legumes examined (Fig. 2). Propagule production was greatest on ironwood pericarps, although differences among legume pericarps were significant (Fisher's protected LSD, $P<0.05$ ) for only one test. Aflatoxin $\mathrm{B}_{1}$ production was significantly higher in mesquite pericarps than in pericarps of other legumes in both tests (Fisher's protected LSD, $P<0.001)$. Mesquite pericarps supported at least 10 times more aflatoxin $B_{1}$ than pericarps of other legumes. There were no significant differences in aflatoxin $\mathrm{B}_{1}$ production in pericarps among ironwood, palo verde, or acacia. Aflatoxin $\mathrm{B}_{1}$ was not detected on ironwood, palo verde, or acacia pericarps for one inoculation experiment.

TABLE 3. In vitro mean propagule and aflatoxin $\mathrm{B}_{1}$ production by Aspergillus flavus (AF-13) in mature seed of various substrates ${ }^{\mathrm{y}}$

\begin{tabular}{lccccc}
\hline & \multicolumn{2}{c}{ Propagules $(\mathrm{CFU} / \mathrm{g})$} & & \multicolumn{2}{c}{ Aflatoxin $\mathrm{B}_{1}(\mu \mathrm{g} / \mathrm{kg})$} \\
\cline { 2 - 3 } \cline { 5 - 6 } Substrate $^{\mathrm{z}}$ & $\mathrm{I}$ & $\mathrm{II}$ & & $\mathrm{I}$ & II \\
\hline Mesquite & $7.3 \times 10^{8} \mathrm{a}$ & $7.0 \times 10^{8} \mathrm{a}$ & & $7.5 \times 10^{3} \mathrm{~b}$ & $6.8 \times 10^{3} \mathrm{~b}$ \\
Palo verde & $3.0 \times 10^{8} \mathrm{~b}$ & $3.5 \times 10^{8} \mathrm{~b}$ & & $1.1 \times 10^{4} \mathrm{~b}$ & $4.4 \times 10^{3} \mathrm{c}$ \\
Cotton & $3.1 \times 10^{8} \mathrm{~b}$ & $3.5 \times 10^{8} \mathrm{~b}$ & & $3.2 \times 10^{5} \mathrm{a}$ & $2.6 \times 10^{5} \mathrm{a}$ \\
Corn & $3.0 \times 10^{8} \mathrm{~b}$ & $3.1 \times 10^{8} \mathrm{~b}$ & & $1.2 \times 10^{3} \mathrm{c}$ & $6.6 \times 10^{2} \mathrm{c}$ \\
\hline
\end{tabular}

y Means followed by different letters within a column are significantly different at $P=0.001$ according to Fisher's protected least significant difference; I and II = experiment 1 and experiment 2 , respectively.

z Mature seeds only.

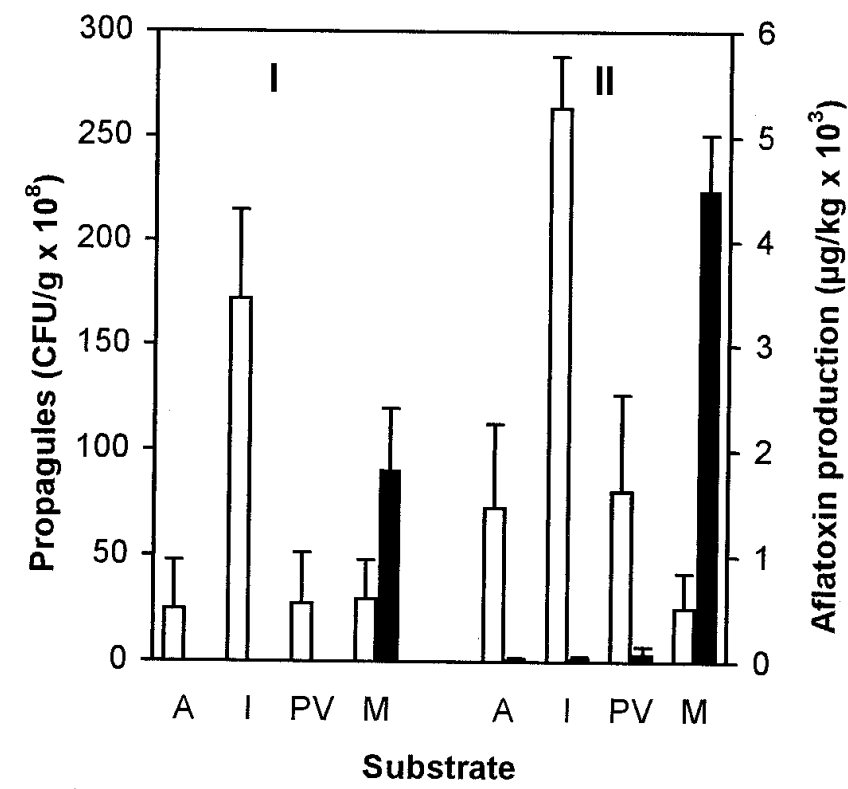

Fig. 2. Density of propagules and aflatoxin $\mathrm{B}_{1}$ produced by Aspergillus flavus in vitro on pericarps of acacia, ironwood, palo verde, and mesquite. $\square=$ $\mathrm{CFU} / \mathrm{g}$ of substrate, $\mathbf{\square}=$ aflatoxin $\mathrm{B}_{1}, \mathrm{I}=$ experiment $1, \mathrm{II}=$ experiment $2, \mathrm{~A}=$ acacia, $\mathrm{I}=$ ironwood, $\mathrm{PV}=$ palo verde, and $\mathrm{M}=$ mesquite. 
Comparison of mesquite seeds and pericarps showed a high capacity of mesquite pod parts to support propagule and aflatoxin $\mathrm{B}_{1}$ production by $A$. flavus (Fig. 3). Mesquite seeds supported significantly higher aflatoxin $\mathrm{B}_{1}$ production than pericarps (ANOVA, $P<0.05$ ), although there were no significant differences in the quantity of $A$. flavus propagules produced on seed or pericarps. Both whole mature and whole immature mesquite pods supported A. flavus growth and aflatoxin $\mathrm{B}_{1}$ production in vitro (Fig. 4). However, mature whole mesquite pods supported significantly (ANOVA, $P<0.005$ ) more aflatoxin $\mathrm{B}_{1}$ production than immature pods in one of two tests. There were no significant differences in CFU per gram between mature and immature pods.

Aflatoxin-producing potential of $\boldsymbol{A}$. flavus isolates. Isolates of $A$. flavus $\mathrm{S}$ and $\mathrm{L}$ strains from mesquite pods were tested for ability to produce aflatoxins. All S strain isolates produced aflatoxin $\mathrm{B}_{1}$, whereas only 8 of $25 \mathrm{~L}$ strain isolates produced detectable levels of aflatoxin. The quantity of aflatoxin $\mathrm{B}_{1}$ produced by 13 of $25 \mathrm{~S}$ strain isolates exceeded the highest quantity produced by an $\mathrm{L}$ strain isolate $\left(230,874 \mu \mathrm{g}\right.$ of aflatoxin $\mathrm{B}_{1} / \mathrm{kg}$ of mycelium). The maximum amount produced by the $\mathrm{S}$ strain was $825,448 \mu \mathrm{g}$ of aflatoxin $\mathrm{B}_{1} / \mathrm{kg}$ of mycelium. The average aflatoxin production for $\mathrm{L}$ strain isolates (including nonproducers) was $15,693 \mu \mathrm{g}$ of aflatoxin $\mathrm{B}_{1} / \mathrm{kg}$ of mycelium, whereas the average aflatoxin production for $\mathrm{S}$ strain isolates was 314,798 $\mu \mathrm{g}$ of aflatoxin $\mathrm{B}_{1} / \mathrm{kg}$ of mycelium. Strain $\mathrm{S}$ isolates tested produced significantly higher levels of aflatoxins than $\mathrm{L}$ strain isolates $(P<0.001$, Student's $t$ test $)$.

Aflatoxins in natural habitats. Aflatoxins were detected in 18 of 94 intact pod and dehisced pericarp samples collected (Table 4). Aflatoxin $B_{1}$ was detected in palo verde, mesquite, and ironwood samples but was not detected in the five pericarp samples of Acacia spp. analyzed. Mesquite and ironwood samples collected from the ground had the highest incidence of aflatoxin contamination, with the aflatoxin content of mesquite exceeding that of ironwood samples. Mesquite pod samples collected directly from trees had less aflatoxin contamination, both in incidence and overall concentration, than mesquite pods collected from the ground. Aflatoxins were not detected in samples of immature mesquite pods. Insect-wounded mesquite pods contained significantly (Student's $t$ test, $P<0.04$ ) greater concentrations of aflatoxin $\mathrm{B}_{1}(0.17$ versus $99 \mu \mathrm{g} / \mathrm{kg})$ and significantly (Student's $t$

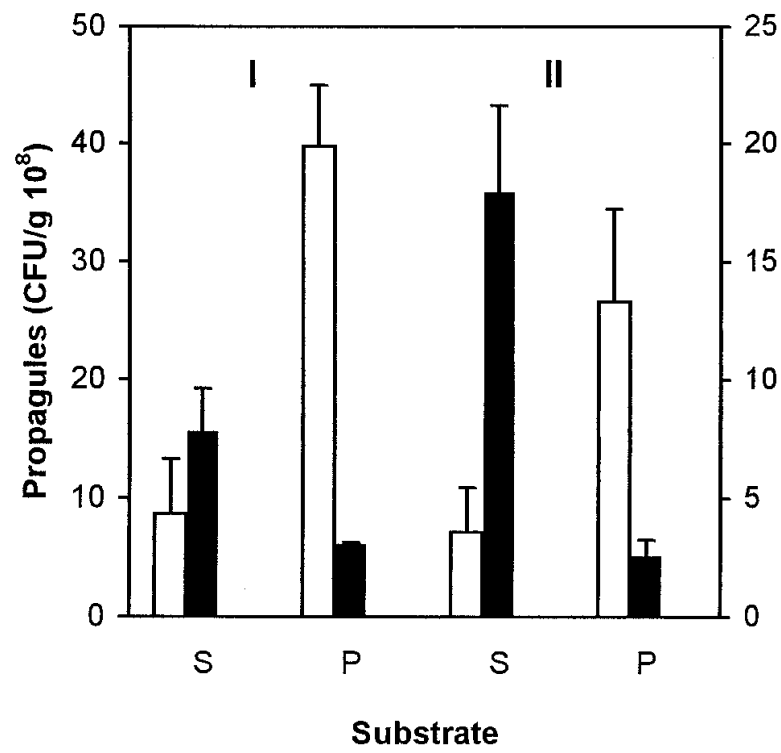

Fig. 3. Density of propagules and aflatoxin $\mathrm{B}_{1}$ produced by Aspergillus flavus in mesquite seed and seedless pericarps. $\square=\mathrm{CFU} / \mathrm{g}$ of substrate, - = aflatoxin $\mathrm{B}_{1}, \mathrm{I}=$ experiment $1, \mathrm{II}=$ experiment $2, \mathrm{~S}=$ seed, and $\mathrm{P}=$ pericarp. test, $P<0.001)$ more propagules $(14,354$ versus $1,437,144 \mathrm{CFU} / \mathrm{g})$ of $A$. flavus than unwounded pods.

\section{DISCUSSION}

Aflatoxin-producing fungi have been reported in arid regions around the world, including agricultural and desert habitats of the Sonoran Desert $(8,36,45)$, where they are frequently associated with plant debris (9). The current study showed the consistent presence of both A. flavus and A. tamarii in legume debris. The $A$. flavus propagule levels found in legume debris indicate a high incidence and concentration of fungi capable of producing aflatoxins. Both the $\mathrm{S}$ and $\mathrm{L}$ strains of A. flavus were consistently found in legume debris. Strain $\mathrm{S}$ isolates produce numerous small sclerotia and fewer conidia than L strain isolates (10). Strain S isolates produce on average more aflatoxin than $\mathrm{L}$ strain isolates (5). The average aflatoxin production by desert legume isolates was higher for $\mathrm{S}$ than $\mathrm{L}$ strain isolates, a result consistent with previous findings $(5,12)$. Incidence of $A$. tamarii and $A$. flavus varied among substrates, with relatively high levels of both species on debris but much lower levels of A. tamarii on pods. Similar but less marked variations were also detected between the $\mathrm{S}$ and $\mathrm{L}$ strains of $A$. flavus in debris and pod samples, with the $\mathrm{S}$ strain occurring at a higher frequency on pods than on debris. Differences in incidence of species or strains on pods and debris of the same plant species may result from differential capacities to exploit nutrients varying among the substrates. Increased incidence of the $\mathrm{S}$ strain on pod samples could also be attributed to uneven sampling in the different areas of Arizona, a region in which marked geographic differences in the distribution of the $\mathrm{S}$ strain of $A$. flavus are known to exist $(10,32,33,39)$.

Although mesquite pods had a lower incidence of $A$. flavus than mesquite debris, the average density of A. flavus in mesquite pods was over 200 times greater than in debris. Thus, when infected, mesquite pods yielded large quantities of A. flavus propagules. The relatively high concentration of propagules on mesquite pods may result from the quality and quantity of nutrients in such pods. A. flavus preferentially uses simple sugars (28) and readily available sucrose may fuel the elevated A. flavus growth and reproduction detected in mesquite pods. The indehiscent mesquite pods contain over $20 \%$ sucrose (wt/wt), mostly local-

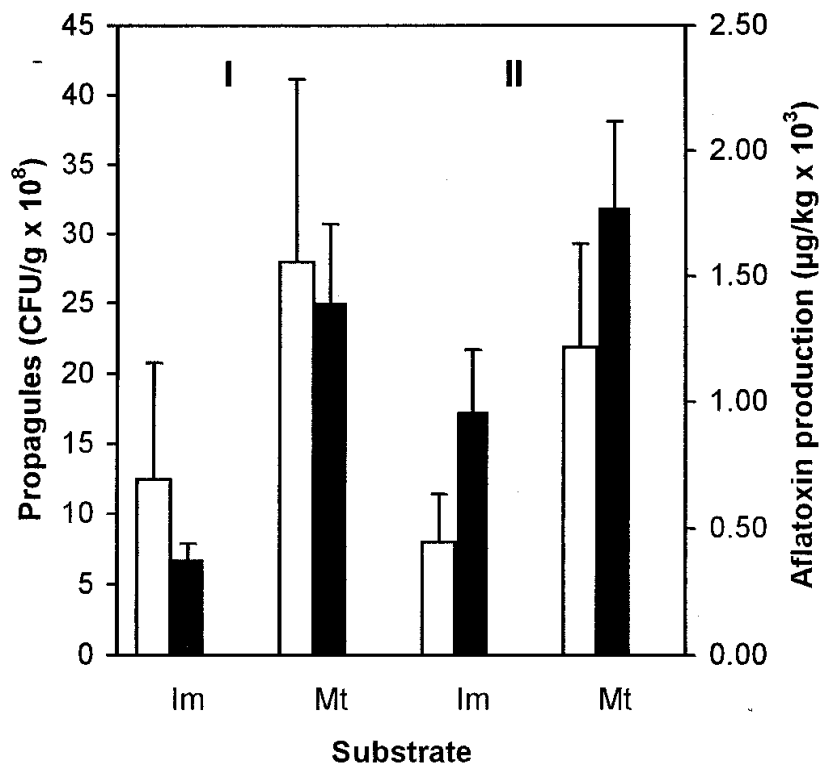

Fig. 4. Density of propagules and aflatoxin $\mathrm{B}_{1}$ produced by Aspergillus flavus in immature and mature whole pods of mesquite. $\square=\mathrm{CFU} / \mathrm{g}$ of substrate, $\boldsymbol{\square}=$ aflatoxin $\mathrm{B}_{1}, \mathrm{I}=$ experiment $1, \mathrm{II}=$ experiment $2, \mathrm{Im}=$ immature pods, and $\mathrm{Mt}=$ mature pods. 
ized in the pericarp, which holds the pods together in a sticky matrix $(16,48)$. The other leguminous trees produce dehiscent pods that lack a sugary pericarp.

Densities of $A$. flavus propagules detected are a direct consequence of environmental, physical, and biological factors affecting the sampled substrate prior to collection. Propagule counts from natural samples will rarely depict the uppermost levels of $A$. flavus propagules a given substrate may yield. In vitro studies reported here show that pods and debris from Sonoran Desert trees can support extensive growth and sporulation of $A$. flavus. Incidence of $A$. flavus and related species can be high in localized areas within the desert environment $(8,9)$. High-incidence areas are centers of reproduction from which A. flavus disperses (9). Desert leguminous trees contribute significant amounts of debris (4), which support such reproductive centers. Thus, accumulated debris of desert leguminous trees harbor reservoirs of $A$. flavus propagules that may disperse to both native substrates and nearby agricultural fields.

Many legumes support both growth of aflatoxin-producing fungi and production of aflatoxins and aflatoxin contamination of pulses occurs in several areas $(18,40)$. In vitro studies presented here indicate that seed of palo verde and mesquite can support aflatoxin production similar to that produced in some conventional crops with aflatoxin contamination problems. Although pericarps of certain perennially contaminated crops support very little or no aflatoxin production, pericarps of desert legumes can support significant aflatoxin biosynthesis, as shown in the current study. Indeed, mesquite pericarps supported production of aflatoxin $B_{1}$ at over $3,000 \mu \mathrm{g} / \mathrm{kg}$ in each of four in vitro tests. The other legume pericarps also supported aflatoxin production in one test. Limited aflatoxin production in pericarps of desert legumes other than mesquite may be a consequence of either inadequate nutrient composition or the presence of compounds inhibitory to aflatoxin biosynthesis (29). However, both the magnitude of mesquite pericarp contamination and the fate of pericarps in the environment should focus our attention on this component. Although significant amounts of aflatoxin can be produced in legume seeds, most desert pods dehisce, releasing the seeds which are quickly scavenged by desert fauna. Thus, aflatoxin in seeds must form prior to pod maturation if significant aflatoxin accumulation is to occur. In contrast, mesquite pods do not split open at maturity to release seed; instead, seed remain embedded in the sugary pericarp until consumed. Frequently, whole or half-chewed mesquite pods accumulate beneath trees, providing opportunity for infection or continued accumulation of aflatoxins. The prolonged association of pericarp and seed caused by the indehiscent nature of mesquite may allow the pericarp to serve as an infection court for subsequent seed infection.
In the current study, insect exit holes were frequently found in whole pods of palo verde and mesquite. Bruchid beetles are a well-known pest of desert leguminous trees and are commonly associated with palo verde and mesquite $(23,25)$. Aflatoxin levels in pods with bruchid beetle exit holes were significantly higher than in unwounded pods. This may indicate that insect damage predisposes leguminous pods to infection and aflatoxin contamination by $A$. flavus. Insect damage is known to predispose many crops to aflatoxin contamination $(7,17,47)$.

Whole pods and seedless pericarps of mesquite with naturally occurring aflatoxins were commonly found throughout the Arizona Sonoran Desert. The sugary pericarp that distinguishes mesquite pods from other legumes must frequently drive pod aflatoxin contamination. Sugars are the first substrate used by A. flavus during aflatoxin production (28), and regulation of sugar utilization is linked to induction of genes in the aflatoxin biosynthesis gene cluster (51). Even immature pods of mesquite supported growth and sporulation of $A$. flavus in vitro, although aflatoxins were not detected in immature pods from the desert. Although palo verde pods from trees and soil, and ironwood pericarps from soil, were found to have naturally occurring aflatoxin $\mathrm{B}_{1}$, pods of Prosopis spp. were the predominant source of aflatoxin contamination in Sonoran Desert habitats identified in the current study. Species of Prosopis abound in many desert habitats worldwide, with several species having pods very similar in composition to the ones assayed in this study. Those Prosopis spp. may similarly serve as significant reservoirs of aflatoxin-producing fungi and as sources of aflatoxins in warm arid habitats worldwide.

Most crops susceptible to aflatoxin contamination undergo rigorous testing procedures to ensure that aflatoxin concentrations are below established levels acceptable for human or animal consumption $(1,14)$. The maximum permissible limit for human consumption in the United States $(20 \mu \mathrm{g} / \mathrm{kg})$ was frequently exceeded in ironwood, palo verde, and mesquite collected from natural habitats. Mesquite pods frequently contained aflatoxin levels above the maximum permitted even in the least stringently regulated feeds $(300 \mu \mathrm{g} / \mathrm{kg})$. Nevertheless, desert fauna habitually feed on pods of palo verde, mesquite, and ironwood $(23,27)$. Thus, desert animals must be exposed to concentrations of aflatoxins previously shown to be toxic and carcinogenic in species of birds, fish, and mammals (14). This exposure might exert detrimental effects on the desert fauna. However, extensive and repeated exposure of animal populations to aflatoxins may have caused selection of reduced sensitivity to aflatoxins within native animal communities $(24,38,50)$. This resistance may mitigate influences of aflatoxins on desert fauna.

Desert tree legumes have been used for centuries as food by native peoples around the world (Southwestern United States,

TABLE 4. Incidence of Aspergillus tamarii and the $\mathrm{S}$ and $\mathrm{L}$ strains of A. flavus and average concentration and incidence of aflatoxin $\mathrm{B}_{1}$ in pods of four common desert legumes in the Sonoran Desert

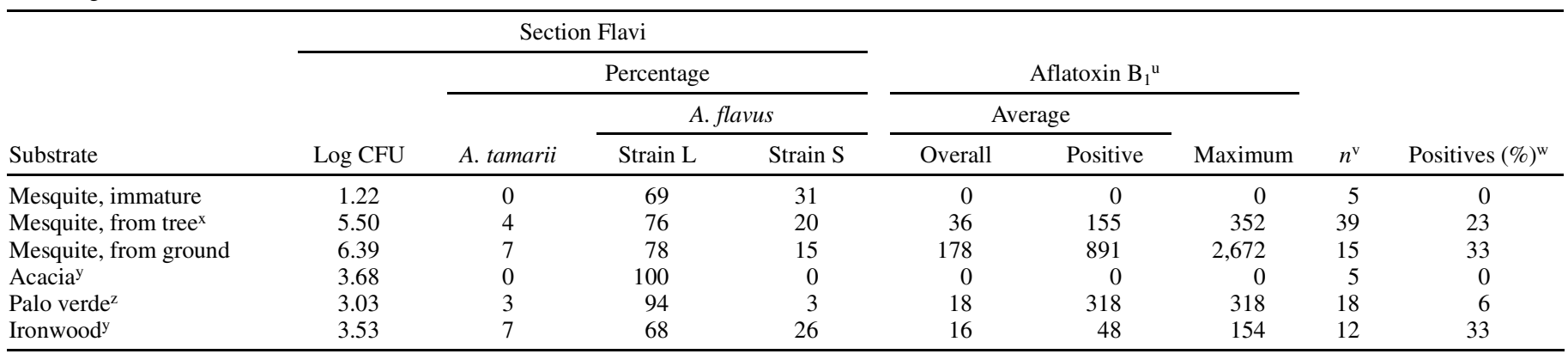

${ }^{\mathrm{u}}$ Expressed in $\mu \mathrm{g} / \mathrm{kg}$. Overall $=$ average of all samples tested. Positive $=$ average of samples with detectable levels of aflatoxin.

${ }^{v}$ Number of samples.

w Percentage of samples with detectable levels of aflatoxin.

${ }^{x}$ Mature pods.

y Only pericarps from ground.

${ }^{\mathrm{z}}$ Both intact pods from tree and dehisced pericarps from ground. 
Central and South America, India, and Asia) $(15,19)$. In many instances, pods were used only occasionally but, in other cases, pods were ground into flour and used regularly as gruel, for bread and cakes, or fermented as a beverage (23). Whether tree legumes were used as a staple or only as an emergency food source, the current results suggest human exposure to aflatoxins occurred via mesquite pods before the advent of an agricultural society. For certain native southwestern cultures that used mesquite pod flour as a staple (e.g., Zuni, Pima, and Seri), perennial exposure was likely a reality. Although limited in scale, modern uses of mesquite include mesquite pod meal and flour alternatives to cereal flours and cattle feed. The current study indicates that nontraditional meals like mesquite may have detrimental aflatoxin levels and aflatoxin monitoring prior to marketing should take place as required for traditional vegetable meals made from susceptible crops (i.e., corn, cottonseed, peanut).

Palo verde and ironwood also have significant potential to accumulate aflatoxin. In vitro ironwood pericarps accumulated aflatoxins and, a few samples of ironwood pericarps contained naturally occurring aflatoxins. In contrast, seedless pericarps of palo verde were never found to contain naturally occurring aflatoxins. However, palo verde seeds have a high potential for aflatoxin accumulation, and inoculation experiments showed a potential for pericarps to produce limited amounts of aflatoxins. Pericarps of ironwood and palo verde in debris under canopies may combine with aborted seed and malformed and undehisced pods to provide a significant source of aflatoxins in natural habitats. Influences of such sources are unlikely to affect most vertebrates. However, invertebrates and microbes are likely to be exposed.

Development of mesquite and other tree legumes as low input crops for developing countries $(20,21)$ with end products for human or animal consumption must take into account potential aflatoxin contamination. Two of the mesquite samples analyzed in this study were mesquite meal intended for human consumption and neither had detectable levels of aflatoxins. However, our study shows a potential for $A$. flavus to contaminate and produce high concentrations of aflatoxin in mesquite pods prior to and after harvest. Currently, pods of mesquite are readily available in some health or cooperative food stores, and mesquite pods and other legume pods are used as alternative animal feed in some countries. In light of this study, desert tree legume products intended for human or animal consumption should be subjected to the same scrutiny for aflatoxin content as traditional crops.

\section{ACKNOWLEDGMENTS}

This work was supported by grants from The Cotton Foundation, The Arizona State Support Program of Cotton Incorporated, The IR-4 Biopesticide Program, and The United States Department of Agriculture Multi-Crop Aflatoxin Elimination Program. We thank T. Youngker and K. Kobbeman for helping with sample collection and M. Palmisano and J. Watkins for general laboratory assistance.

\section{LITERATURE CITED}

1. Applebaum, R. S., Brackett, R. E., Wiseman, D., and Marth, E. H. 1982. Aflatoxin: Toxicity to dairy cattle and occurrence in milk and milk products-A review. J. Food Prot. 45:752-777.

2. Ayde, J., and Mateles, R. I. 1964. Incorporation of labeled compounds into aflatoxins. Biochim. Biophys. Acta 86:418-420.

3. Bailey, A. W. 1976. Nitrogen fixation in honey mesquite seedlings. J. Range Manage. 29:479-481.

4. Barth, R. C., and Klemmedson, J. O. 1982. Amount and distribution of dry matter, nitrogen, and organic carbon in soil-plant systems of mesquite and palo verde. J. Range Manage. 35:412-418.

5. Bayman, P., and Cotty, P. J. 1993. Genetic diversity in Aspergillus flavus: Association with aflatoxin production and morphology. Can. J. Bot. 71:23-31.

6. Benson, L., and Darrow, R. A. 1981. Trees and Shrubs of the Southwestern Deserts. The University of Arizona Press, Tucson.
7. Beti, J. A. 1995. Effects of maize weevils (Coleoptera:Curculionidae) on production of aflatoxin $\mathrm{B}_{1}$ by Aspergillus flavus in stored corn. J. Econ. Entomol. 88:1776-1782.

8. Boyd, M. L., and Cotty, P. J. 1998. Characterization of Aspergillus section Flavi communities from natural habitats in the Sonoran Desert. (Abstr.) Inoculum 49:11.

9. Boyd, M. L., and Cotty, P. J. 1998. Spatiotemporal distribution and density of Aspergillus section Flavi propagules in Sonoran Desert habitats. (Abstr.) Phytopathology 88:S10.

10. Cotty, P. J. 1989. Virulence and cultural characteristics of two Aspergillus flavus strains pathogenic to cotton. Phytopathology 79:808-814.

11. Cotty, P. J. 1994. Comparison of four media for the isolation of Aspergillus flavus group fungi. Mycopathologia 125:157-162.

12. Cotty, P. J. 1997. Aflatoxin-producing potential of communities of Aspergillus section Flavi from cotton producing areas in the United States. Mycol. Res. 101:698-704.

13. Cotty, P. J., and Bayman, P. 1993. Competitive exclusion of a toxigenic strain of Aspergillus flavus by an atoxigenic strain. Phytopathology 83: 1283-1287.

14. Cotty, P. J., Bayman, P., Egel, D. S., and Elias, K. S. 1994. Agriculture, aflatoxins and Aspergillus. Pages 1-27 in: The Genus Aspergillus: From Taxonomy and Genetics to Industrial Applications. K. A. Powell, A. Renwick, and J. F. Peberdy, eds. Plenum Press, New York.

15. D'Antoni, H. L., and Solbrig, O. T. 1977. Algarrobos in South American cultures past and present. Pages 189-199 in: Mesquite, its Biology in Two Desert Scrub Ecosystems. B. B. Simpson, ed. Dowden, Hutchinson \& Ross, Inc., Stroudsburg, PA.

16. Del Valle, F. R., Escobedo, M., Muñoz, M. J., Ortega, R., and Bourges, H. 1983. Chemical and nutritional studies on mesquite beans (Prosopis juliflora). J. Food Sci. 48:914-919.

17. Dowd, P. F. 1998. Involvement of arthropods in the establishment of mycotoxigenic fungi under field conditions. Pages 307-350 in Mycotoxins in Agriculture and Food Safety. K. K. Sinha and D. Bhatnagar, eds. Marcel Dekker, Inc., New York.

18. El-Kady, I. A., Mohamed El-Maraghy, S. S., and Zohri, A. A. 1991. Mycotoxin production on different cultivars and lines of broad bean (Vicia faba L.) seeds in Egypt. Mycopathologia 113:165-169.

19. Felger, R. S. 1977. Mesquite in Indian cultures of southwestern North America. Pages 150-176 in: Mesquite, its Biology in Two Desert Scrub Ecosystems. B. B. Simpson, ed. Dowden, Hutchinson \& Ross, Inc., Stroudsburg, PA.

20. Felker, P. 1981. Uses of tree legumes in semiarid regions. Econ. Bot. 35:174-186.

21. Felker, P., and Bandurski, R. S. 1980. Uses and potential uses of leguminous trees for minimal energy input agriculture. Econ. Bot. 33:172-184.

22. Gourinath, A., and Manoharachary, C. 1990. Mycoflora associated with gummy exudates of some plants. Geobios New Rep. 9:65.

23. Havard, V. 1884. The mesquite. Am. Nat. 18:451-459.

24. Herrera, J., Walters, L. L., and Freeman, G. R. 2000. Aflatoxin consumption by the food storing rodent, Dipodomys spectabilis. (Abstr.) Inoculum $51: 35$.

25. Kingsolver, J. M., Johnson, C. D., Swier, S. R., and Teran, A. 1977. Prosopis fruits as a resource for invertebrates. Pages 108-122 in: Mesquite, its Biology in Two Desert Scrub Ecosystems. B. B. Simpson, ed. Dowden, Hutchinson \& Ross, Inc., Stroudsburg, PA.

26. Klich, M. A., and Pitt, J. I. 1988. Differentiation of Aspergillus flavus from A. parasiticus and other closely related species. Trans. Br. Mycol. Soc. 91:99-108.

27. Mares, M. A., Enders, F. A., Kingsolver, J. M., Neff, J. L., and Simpson, B. B. 1977. Prosopis as a niche component. Pages 123-149 in: Mesquite, its Biology in Two Desert Scrub Ecosystems. B. B. Simpson, ed. Dowden, Hutchinson \& Ross, Inc., Stroudsburg, PA.

28. Mellon, J. E., Cotty, P. J., and Dowd, M. K. 2000. Influence of lipids with and without other cottonseed reserve materials on aflatoxin $\mathrm{B}_{1}$ production by Aspergillus flavus. J. Agric. Food Chem. 48:3611-3615.

29. Mellon, J. E., Cotty, P. J., Godshall, M. A., and Roberts, E. 1995. Demonstration of aflatoxin inhibitory activity in a cotton seed coat xylan. Appl. Environ. Microbiol. 61:4409-4412.

30. Mooney, H. A., Simpson, B. B., and Solbrig, O. T. 1977. Phenology, morphology, physiology. Pages 26-43 in: Mesquite, its Biology in Two Desert Scrub Ecosystems. B. B. Simpson, ed. Dowden, Hutchinson \& Ross, Inc., Stroudsburg, PA.

31. Official Methods and Recommended Practices of the American Oil Chemists' Society, 5th ed. 1998. D. Firestone, ed. American Oil Chemists' Society, Champaign, IL.

32. Orum, T. V., Bigelow, D. M., Cotty, P. J., and Nelson, M. R. 1999. Using predictions based in geostatistics to monitor trends in Aspergillus flavus strain composition. Phytopathology 89:761-769.

33. Orum, T. V., Bigelow, D. M., Nelson, M. R., Howell, D. R., and Cotty, P. J. 1997. Spatial and temporal patterns of Aspergillus flavus strain compo- 
sition and propagule density in Yuma County, Arizona, Soils. Plant Dis. 81:911-916.

34. Pitt, J. I., Hocking, A. D, and Glenn, D. R. 1983. An improved medium for the detection of Aspergillus flavus and A. parasiticus. J. Appl. Bacteriol. 54:109-114.

35. Pons, W. A., Robertson, J. A., and Goldblatt, L. A. 1966. Collaborative study on the determination of aflatoxins in cottonseed products. J. Am. Oil Chem. Soc. 43:655-669.

36. Ranzoni, F. V. 1968. Fungi isolated in culture from soils of the Sonoran Desert. Mycologia 60:356-371.

37. Raper, K. B., and Fennel, D. I. 1965. The genus Aspergillus. Williams \& Wilkins, Baltimore, MD.

38. Rodeheaver, D. P., Wyatt, R. D., and Marks, H. L. 1986. Relationship of serum a-amylase to aflatoxin resistance in Japanese quail. Avian Dis. 30:568-573.

39. Saito, M., Tsuruta, O., Siriacha, P., Kawasugi, S., Manabe, M., and Buangsuwon, D. 1986. Distribution and aflatoxin productivity of the atypical strains of Aspergillus flavus isolated from soils in Thailand. Proc. Jpn. Assoc. Mycotoxicol. 24:41-46.

40. Singh, P., Bhagat, S., and Ahmad, S. K. 1990. Aflatoxin elaboration and nutritional deterioration in some pulse cultivars during infestation with $A$. flavus. J. Food Sci. Technol. 27:60-62.

41. Sinha, A. K., and Ranjan, K. S. 1990. Incidence of aflatoxins in food grains during flood and post flood period at North Bihar. Proc. Indian
Natl. Acad. B56:295-298.

42. Sinha, B. K., Ranjan, K. S., and Pandey, T. N. 1997. Aflatoxin levels in commonly used pulses in Bihar. Indian J. Nutr. Diet. 34:225-229.

43. Sinha, R. K. 1980. Aflatoxin contamination in some proteinaceous seeds. Biol. Bull. India 2:76-77.

44. Siri, M. C., Echeverría, N. E. 1991. Determinación de microorganismos en semillas de Prosopis alba. IFONA-Rep. 1:33-34.

45. Skujinš, J. 1984. Microbial ecology of desert soils. Adv. Microb. Ecol. 7:49-91.

46. Sokal, R. R., and Rolf, F. J. 1981. Biometry. W. H. Freeman \& Co., San Francisco.

47. Stephenson, L. W., and Russell, T. E. 1974. The association of Aspergillus flavus with hemipterous and other insects infesting cotton bracts and foliage. Phytopathology 64:1502-1506.

48. Walton, G. P. 1923. A chemical and structural study of mesquite, carob and honey locust beans. U.S. Dep. Agric. Bull. 1194:1-19.

49. Windstrom, N. W. 1979. The role of insects and other plant pests in aflatoxin contamination of corn, cotton, and peanuts-A review. J. Environ. Qual. 8:5-11.

50. Wyatt, R. D., Marks, H. L., and Manning, R. O. 1987. Selection for resistance to aflatoxin in chickens. Poult. Sci. 66:1901-1904.

51. Yu, J., Chang, P., Bhatnagar, D., and Cleveland, T. E. 2000. Cloning of a sugar utilization gene cluster in Aspergillus parasiticus. Biochim. Biophys. Acta 1493:211-214. 